\title{
A NEW METHOD FOR ESTIMATING SERUM ACID PHOSPHATASE \\ OF PROSTATIC ORIGIN APPLIED TO THE CLINICAL IN- VESTIGATION OF CANCER OF THE PROSTATE ${ }^{1,2}$
}

\author{
By WILLIAM H. FISHMAN, R. M. DART, C. D. BONNER, W. F. LEADBETTER, \\ F. LERNER, AND F. HOMBURGER \\ (From the Cancer Research and Cancer Control Unit and the Departments of Surgery, Medicine, \\ Biochemistry, and Nutrition, Tufts College Medical School, Boston, Massachusetts, \\ and the Biochemistry Laboratory of the Holy Ghost Hospital, \\ Cambridge, Mass.)
}

(Submitted for publication May 20, 1953; accepted June 17, 1953)

Since the studies of Gutman and Gutman $(2,3)$, measurements of the serum acid phosphatase have become a recognized and widely used ancillary procedure for the diagnosis of cancer of the prostate and a practical means for the evaluation of the functional status of the tumor in many patients with metastasizing cancer of the prostate. While an abnormally increased value of serum acid phosphatase is considered to be a specific index for the presence of carcinoma of the prostate, a normal serum acid phosphatase value in itself cannot be interpreted as signifying absence of this disease. According to Bodansky and Bodansky (4) in their review of the literature, only 24 per cent of unselected patients without and 81 per cent with bone metastases from cancer of the prostate show elevated serum acid phosphatase values. Thus, 20 to 75 per cent of proven cases of cancer of the prostate show equivocal or normal serum acid phosphatase levels.

Attempts have been made to render the determination of serum acid phosphatase more specific for cancer of the prostate. Thus, a search has been made for substrates which would be split prefer-

\footnotetext{
1 This investigation was supported in part by a grantin-aid of the American Cancer Society, Massachusetts Division, the U. S. Public Health Service, National Cancer Institute (Cancer Control Division), Bethesda, Maryland, and by funds from an Institutional Grant of the American Cancer Society, Inc., New York, N. Y. The helpful cooperation of Drs. J. Hartwell Harrison (Peter Bent Brigham Hospital), L. Gottlieb, L. F. H. Taylor (Boston City Hospital), and A. d'Agostino, is gratefully acknowledged. The testosterone used in this study was kindly provided by the Organon Company, Nutley, New Jersey, and by the Schering Corporation, Bloomfield, New Jersey.

2 Presented before the Forty-Fourth Annual Meeting of the American Association for Cancer Research (1), April 9, 1953.
}

entially by the prostatic acid phosphatase in the serum (5). In addition, limited success in the improvement of clinical performance has been claimed by Herbert (6) for the use of ethyl alcohol as an inhibitor of prostatic acid phosphatase and by Abdul-Fadl and King (7) for formalin inhibition of interfering red cell acid phosphatase present in hemolyzed sera.

Fishman and Lerner recently reported a method for estimating serum acid phosphatase of prostatic origin (8) which is based on the inhibitory action of L-tartrate on prostatic acid phosphatase (9). It was found that activity of prostatic acid phosphatase added in vitro to serum could be quantitatively measured and that under the circumstances existing in humans, only a small fraction of the serum acid phosphatase arose from the prostate. This fraction was increased in the presence of cancer of the prostate (8).

This paper constitutes a report of the clinical experience obtained with this new method for the determination of serum acid phosphatase of prostatic origin in some 200 patients, including twentyone subjects with proven prostatic carcinoma.

\section{METHODS AND CLINICAL MATERIAL}

The present method for estimating prostatic acid phosphatase in serum yields two values; one is the so-called "Total" (T) acid phosphatase expressed in King-Armstrong units (mg. phenol liberated in one hour from phenylphosphate under standardized conditions), and the other is "Prostatic" ( $P$ ) acid phosphatase expressed in the same $K$. A. units, but representing that amount of the total serum acid phosphatase which is inhibited by L-tartrate. All sera were assayed for both $T$ and $P$ serum acid phosphatase.

The aged control subjects were hospitalized at the Holy Ghost Hospital, Cambridge, and at the Jewish Memorial Hospital, Roxbury. Ambulatory patients were studied at the Boston Dispensary. Long term study of pa- 


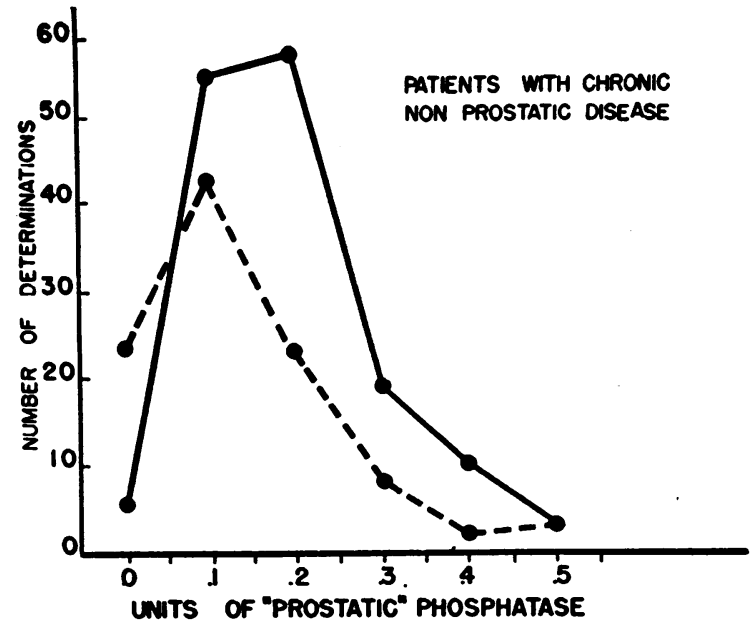

Fig. 1. A Study of the Distribution of Values for "Prostatic" Acid Phosphatase in a Population of Elderly, Chronically-Ill Patents

The solid line represents data obtained in males and the broken line, in females. tients with cancer of the prostate was carried out mainly at the Holy Ghost Hospital, Cambridge. Most of the surgical cases were studied at the New England Center Hospital.

The normal or non-pathological range for total acid phosphatase is here taken as 0.5 to $5.0 \mathrm{~K}$. A. units.

In view of our yet limited experience with the new method, tentative working standards have been used in order to evaluate the clinical worth of the method. Accordingly at this time normal limits for prostatic acid phosphatase are given as 0 to 0.5 units and abnormal values begin with 0.6 units.

Data on the reproducibility of the analytical method have been published (8).

In the cases with "proven cancer of the prostate" this diagnosis was based on the histopathological examination of prostatic tissue unless otherwise stated. In some cases where no biopsy could be performed the findings of a stony hard nodular prostate with bone metastases and elevated total acid phosphatase were accepted as sufficient evidence that cancer of the prostate was present (Patients B., C., D., and H.).

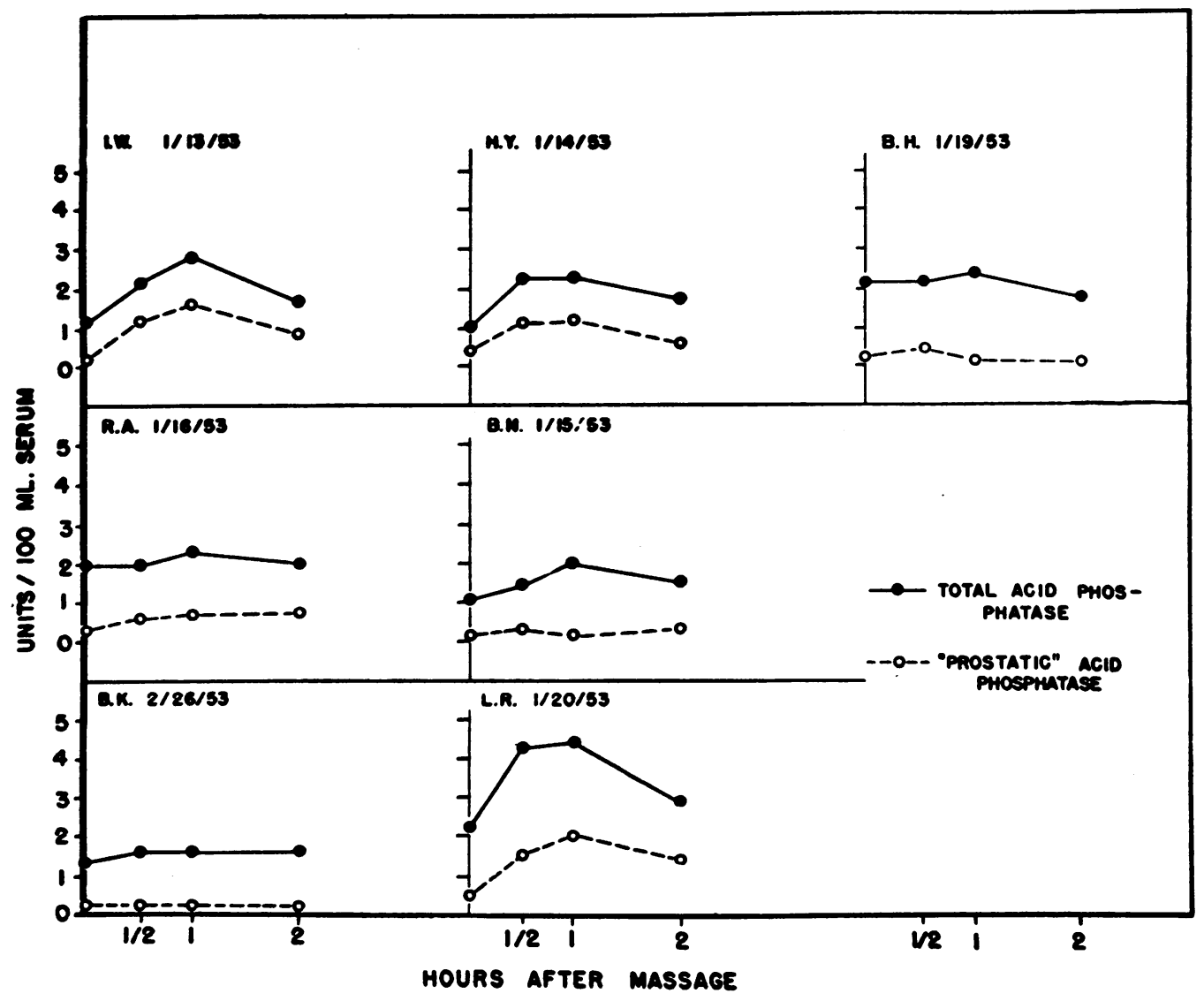

Fig. 2. Effect of Prostatic Massage on Serum Total and "Prostatic" Actd Phosphatases

Patients B. H. and I. W. were massaged for five minutes, the remaining subjects for two minutes. B. $H$. at an earlier date had undergone a prostatectomy. 


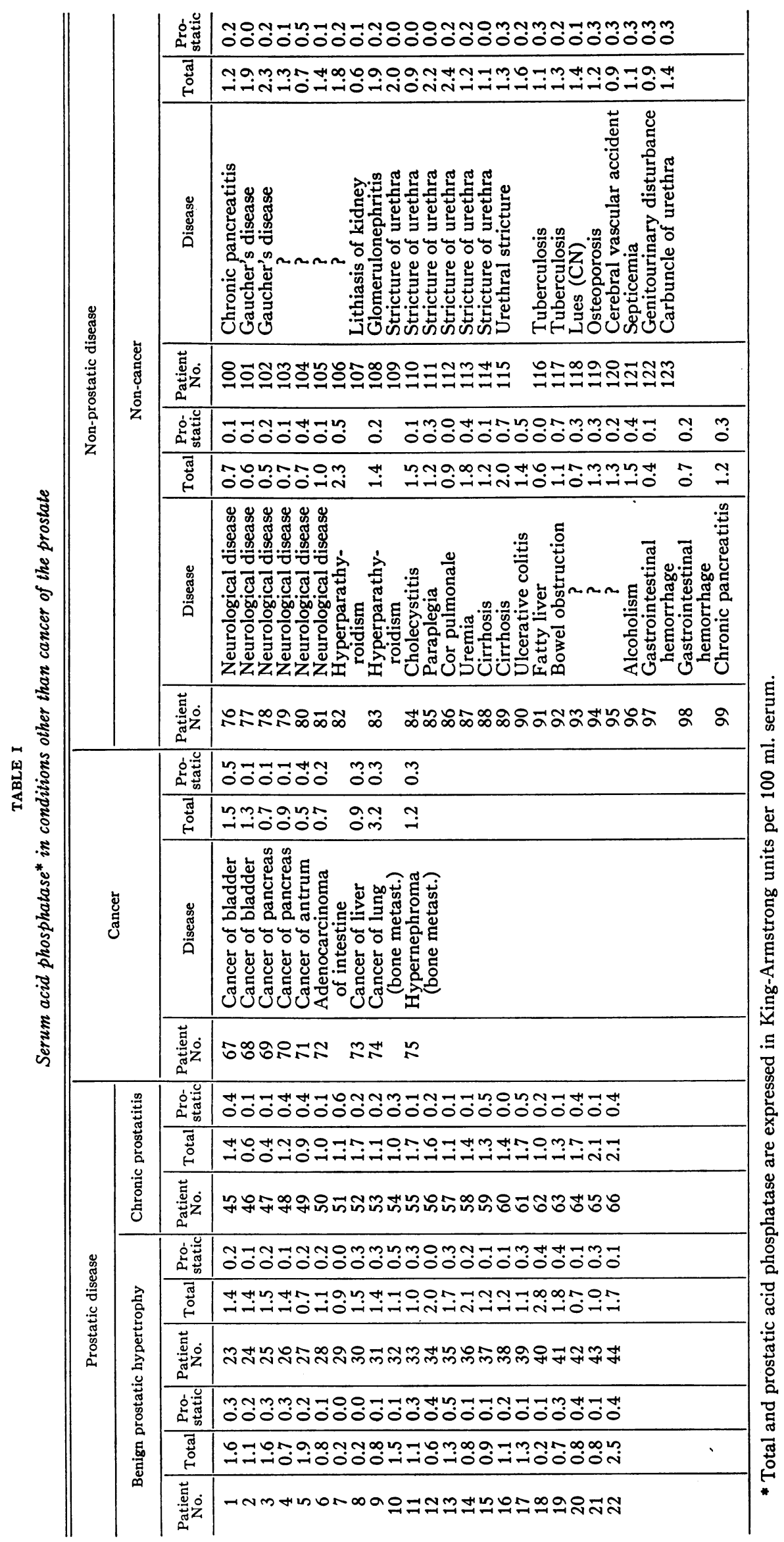


TABLE II

Serum acid phosphatase* in proven prostatic carcinoma

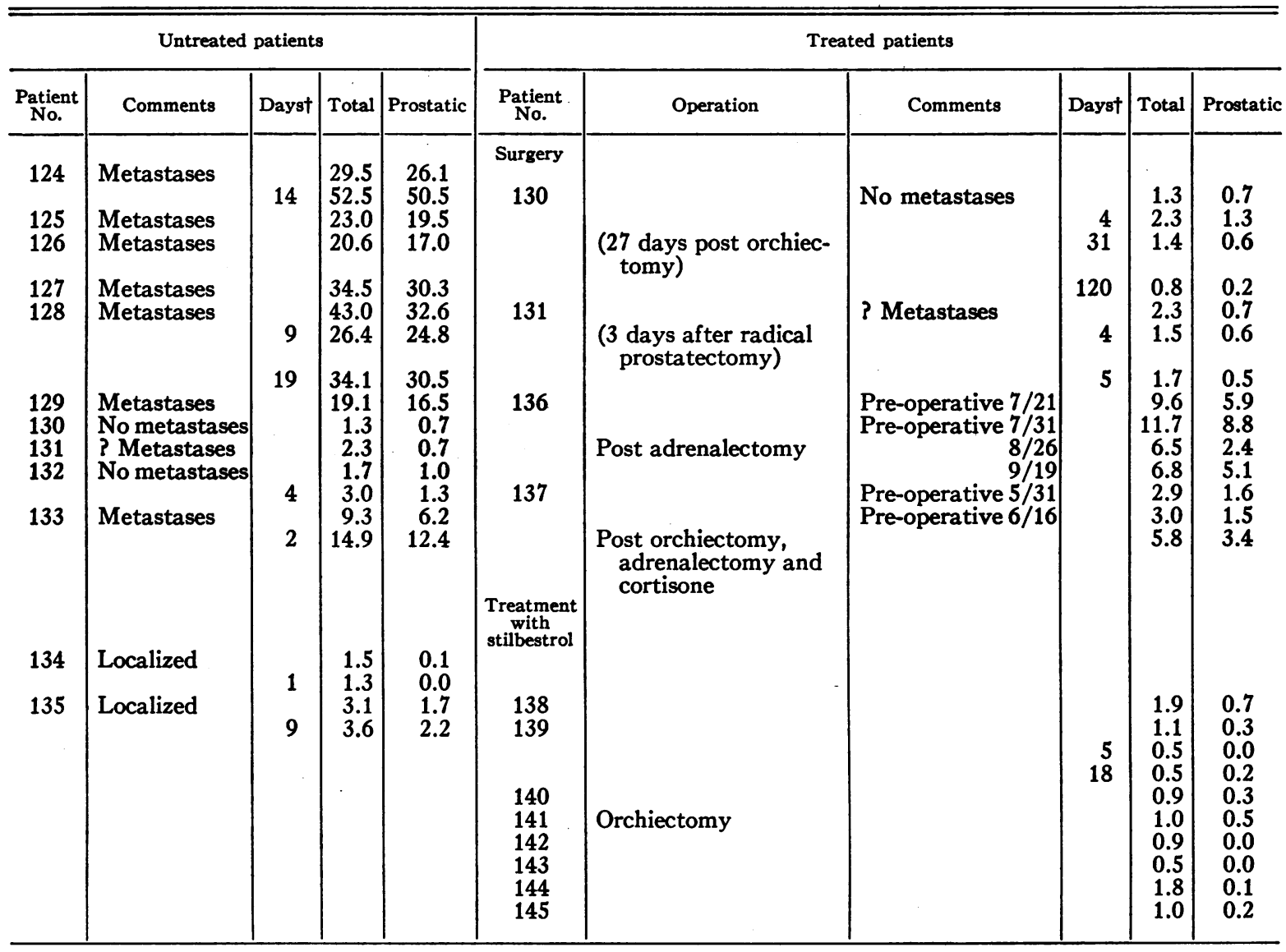

* Total and prostatic acid phosphatase are expressed in King-Armstrong units per 100 ml. serum.

$\dagger$ Days after first phosphatase determination.

\section{RESULTS}

Serum "prostatic" acid phosphatase in aged chronically-ill men and women

A study was made of the normal distribution of the prostatic serum acid phosphatase in a group of 100 elderly male and 50 female patients hospitalized in institutions for the chronically ill. Figure 1 shows the distribution curves obtained. The striking features are the absence of any values of more than 0.5 units of "prostatic" acid phosphatase in these patients, and the difference between the distribution of the serum enzyme values in men and in women.

Benign prostatic hypertrophy, chronic prostatitis and non-prostatic cancer

In 123 patients distributed in these categories, only rarely (in 3 individuals) did a value for "prostatic" acid phosphatase greater than 0.5 units per $100 \mathrm{cc}$. of serum appear (Table I).

\section{Prostatic massage}

The effects of prostatic massage with respect to the serum acid phosphatase were variable (Figure 2 ). However, the "prostatic" fraction showed increases following massage which exceeded the normal levels more often than did the "total" acid phosphatase. Thus, in four of the seven cases cited, the "prostatic" and phosphatase rose above 0.5 units whereas in only two cases did the total acid phosphatase rise above 3.5 units.

\section{Cancer of the prostate}

Untreated cancer of the prostate. Twelve patients were studied: In seven, metastatic lesions in bone were demonstrated by $\mathrm{x}$-ray, in four only 


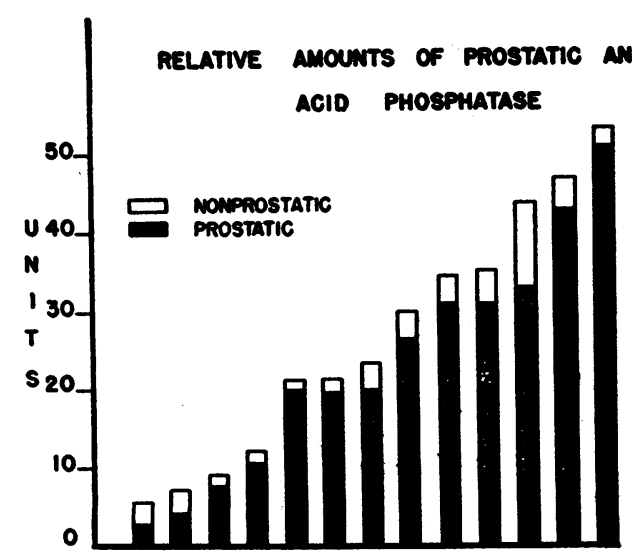

Fig. 3. Individual Sera of Patients with Cancer of the Prostate, Arranged in Ascending Values of Total Acid Phosphatase

Note the large proportion of L-tartrate-inhibited acid phosphatase. Units are the conventional King-Armstrong units.

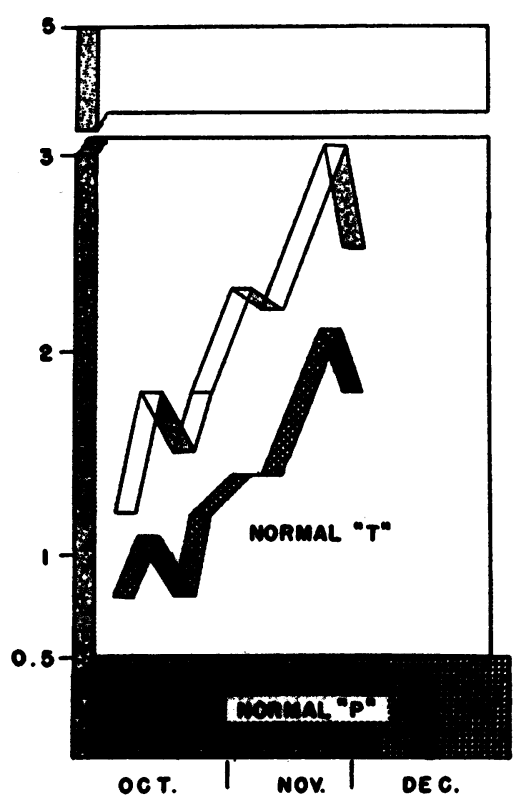

Fig. 4. Patient B. Total Acto Phosphatase (T) and "Prostatic" Acid Phosphatase Expressed in KingArmstrong Units Per $100 \mathrm{cc}$. Serum in a Patient with Clinical Canckr of the Prostate without Skgletal Metastases

The light ribbon represents total and the checkered ribbon "prostatic" acid phosphatase. The normal limits for each are shown in the light and dark shaded areas. In every instance the "prostatic" component was in the pathological range, while the total acid phosphatase was well within normal limits.

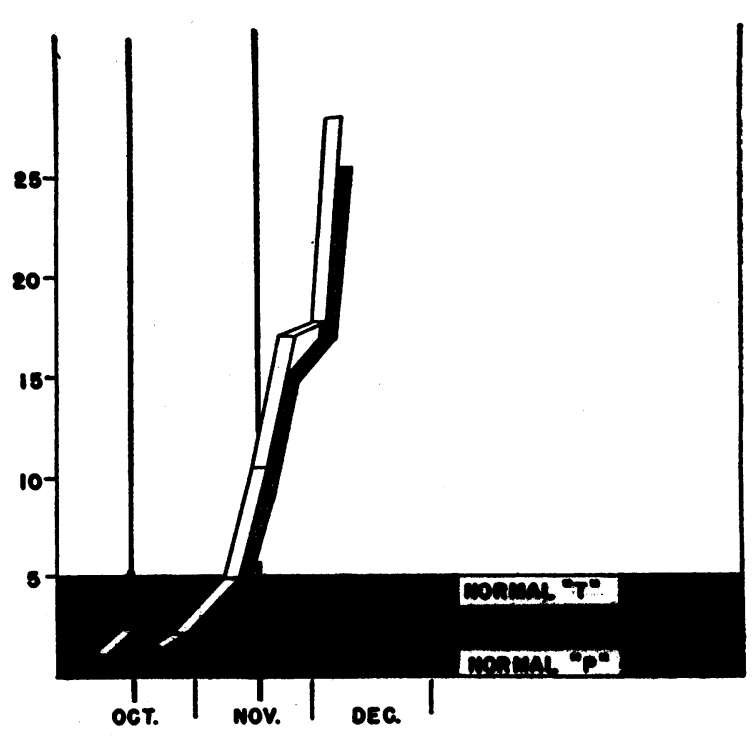

Fig. 5. A Study of a Patient with Cancer of the Prostate Showing Skeletal Metastases Illustrating the Elegation in the "Prostatic" Acid Phosphatase of the Serum (Checkered Ribbon) Which Préceded the Rise in Total Acid Phosphatase (Light RIBBon) IN KING-ARMSTRong UNITS

localized prostatic lesions were present, and in one the possibility of metastases could not be ruled out. In this series of patients, both total and "prostatic" acid phosphatase values were found in the pathological range in the seven subjects with metastases (Table II).

On the other hand, five patients with proven prostatic cancer without evidence of metastases. (Patients 130, 131, 132, 134, 135) gave values for acid phosphatase between 1.3 and 3.0 King-Armstrong units, i.e., well within the normal range. Of these five subjects, four gave results for the serum "prostatic" acid phosphatase of 0.7 to 2.2 units. These are regarded at this time as abnormal values. The fifth patient gave results for both types of serum enzyme within normal limits ( $\mathrm{Pa}$ tient 134). The prostatic pathologic lesion was as. follows :

\section{Patient No.}

(Co) 130: Rectal examination showed a hard nodular prostate markedly enlarged and fixed to the pelvic wall. Needle biopsy: adenocarcinoma.

(Pa) 131 : Histologic examination after radical prostatectomy, in spite of negative needle biopsy, showed adenocarcinoma of the prostate. Gross description: prostate gland together with prostatic urethra and seminal vesicles: 
showing carcinoma involving the left lobe of the prostate and base of the left seminal vesicle.

(Bu) 132: Transurethral prostatectomy three years ago (Massachusetts General Hospital) showed adenocarcinoma of the prostate. The prostate is at present rocky hard and four to five times normal size. Clinically, cancer of prostate.

(Do) 134: The pathological specimen showed a localized carcinoma of $1 \mathrm{~cm}$. in diameter, infiltrating the prostatic capsule and the wall of one seminal vesicle.

(Wa) 135: Clear-cut localized cancer of the prostate by clinical examination.

Figure 3 illustrates the fact that in all instances where the total serum acid phosphatase was found elevated, this increase of enzymatic activity was due largely to the "prostatic" component.
Estrogen therapy in prostatic cancer (Table II). All eight patients with proven carcinoma of the prostate whose disease was controlled by estrogen therapy showed normal values for the total acid phosphatase ranging from 0.5 to 1.9 units. One of these had an abnormal "prostatic" value (0.7).

Surgery and prostatic cancer. Four patients were followed after surgical operations (Table II). The pre-operative studies on two of these have already been discussed (Patients 130,131 ).

In Patient 130, who underwent bilateral orchiectomy, the serum acid phosphatase was never abnormal. However, the "prostatic" fraction was elevated ( 0.7 to 1.3 units) before the orchiectomy and fell thereafter, reaching a normal level (0.2 units) some three months after this operation.

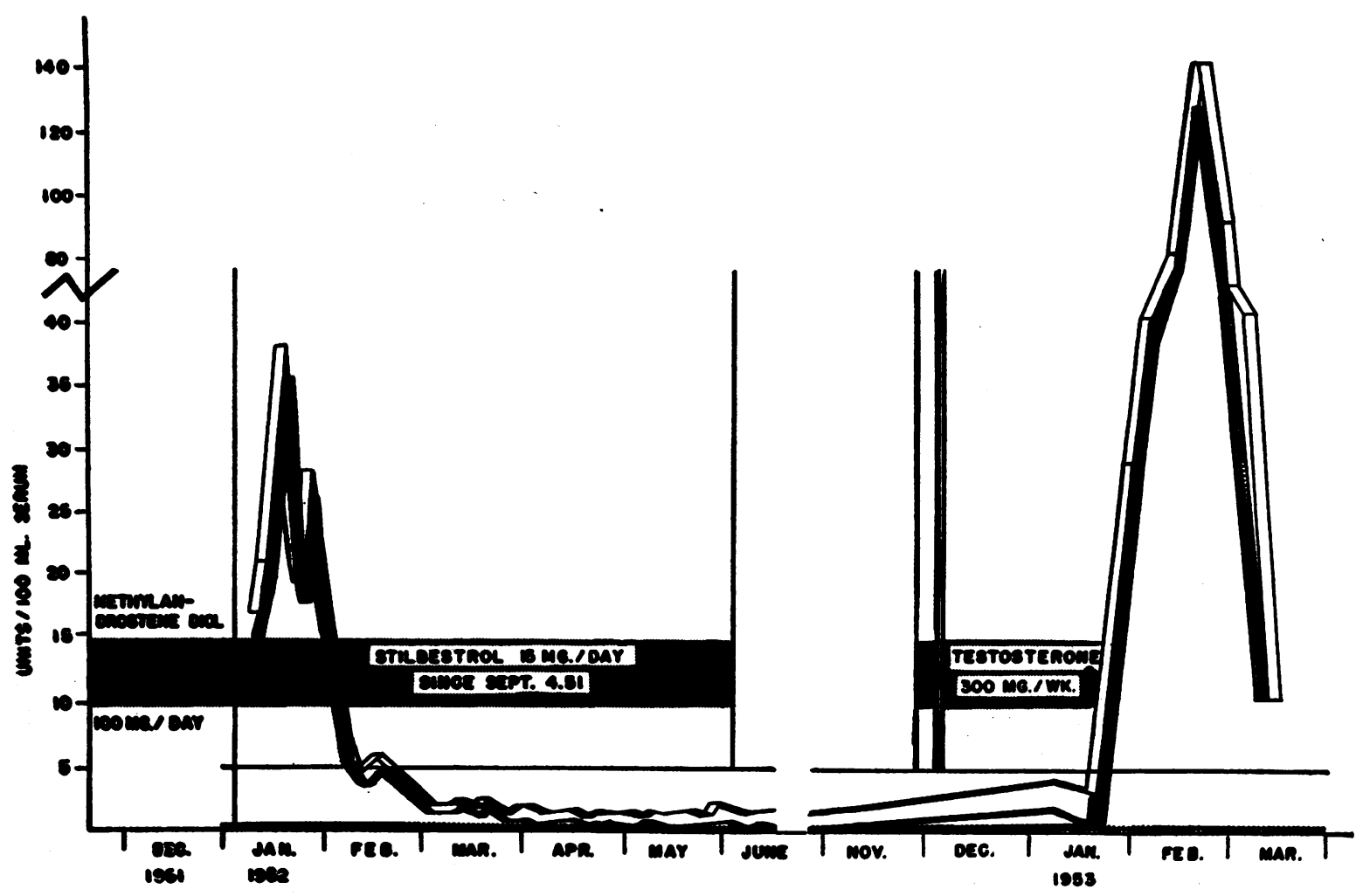

Fig. 6. Clinical Summary. Patient C., White, Male, 75 Years Old

Urinary obstruction and clinical evidence of cancer of the prostate in 1950. Osteoblastic and osteolytic metastases to pelvis and spine. First estrogen therapy was given in 1950, later interrupted, and resumed September 4, 1951. Between November, 1950, and April, 1951, there was marked progression of metastases in spite of X-ray therapy. Orchiectomy was refused. The dosage of Stilbestrol used varied from 10 to $15 \mathrm{mg}$. per day and was well tolerated. The patient, who also suffers from generalized arteriosclerosis, is at present quite well clinically without symptoms referable to his prostatic tumor (enlarged, hard, nodular prostate) and in spite of $x$-ray evidence of widespread metastases. Light ribbon is $T$ phosphatase and checkered ribbon is $\mathbf{P}$ phosphatase. Note the changes of acid phosphatase occurring with various androgen therapy. 


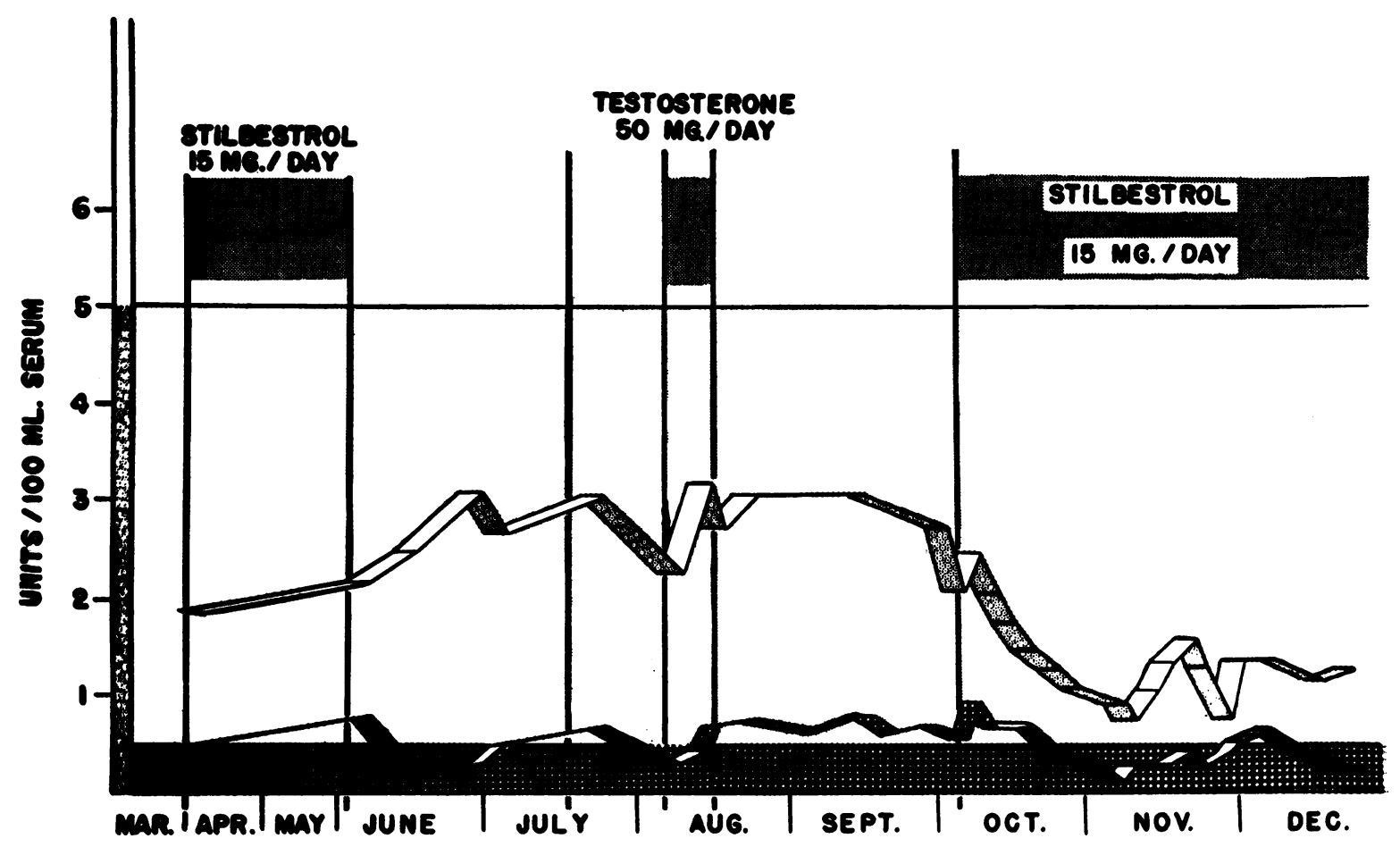

Fig. 7. Patient N., White, Male of 80

Cancer of the prostate diagnosed January, 1951, by rectal examination. At that time there was evidence of anemia, hgb., $9 \mathrm{Gm}$., and elevated serum acid phosphatase, but $\mathrm{x}$-ray studies did not reveal metastases. Repeated $\mathrm{x}$-ray studies one month later showed osteolytic and osteoblastic metastases in right femur. May, 1951, fracture of right hip. Course from beginning of study (March, 1953) has been progressively downhill. Light ribbon is $\mathrm{T}$ phosphatase and checkered ribbon is $\mathrm{P}$ phosphatase.

In the presence of a normal acid phosphatase value in Patient 131 the "prostatic" component was elevated before a radical prostatectomy and bilateral vasoligation was done and showed a trend towards normal levels thereafter, which may, however, not be significant.

In Patient 136 both "prostatic" and total acid phosphatase remained in the pathological range following orchiectomy and bilateral adrenalectomy.

In Patient 137 (previous bilateral orchiectomy and now bilateral adrenalectomy) the serum acid phosphatase was not abnormal until some time after the last operation, whereas the "prostatic" component was elevated (1.6 to 3.4 units) throughout the course of the disease.

In several patients who were studied following total prostatectomy, "prostatic" acid phosphatase levels of up to 0.5 units have been observed although lower values than this were the rule. This amount is believed to represent non-prostatic sources of acid phosphatase which are inhibited by L-tartrate
(11). In our experience so far, this non-prostatic source does not interfere in the interpretation of the values for "prostatic" acid phosphatase.

\section{Long-term study of cancer of prostate}

Long-term studies comparing results of conventional serum acid phosphatase determinations and the present method in prostatic cancer in patients. undergoing hormonal therapy are illustrated in Figures 4 through 9.

The clinical histories in summary of the patients. studied are found in the legends of these figures.

No therapy. Six patients have been studied. Two typical untreated cases are illustrated in Figures 4 and 5. The two enzyme levels were found to parallel each other. However, in Figure4 it is evident that throughout a three-month period the serum total acid phosphatase was within the normal range, even though rising, whereas the "prostatic" component was in the pathological 
range from the very beginning of the observation period (see also Table III). Figure 5 shows that in another patient the level of "prostatic" acid phosphatase indicated an abnormal value more than a month before there was any abnormality evident from study of the serum total acid phosphatase.

Hormonal therapy. Figures 6, 7, and 8 illustrate the point that the "prostatic" acid phosphatase level reflects in identical fashion to the serum total acid phosphatase the response or sometimes lack of response of the enzyme to hormone action. In addition, it seems clear that the "prostatic" component provides a more sensitive and accurate index of activity of prostatic cancer. Figure 8 shows a marked spontaneous downward change towards normal levels which occurred simultaneously in both enzyme fractions. Stilbestrol, which was given later, did not further depress the serum
TABLE III

Patient B.TA systematic long-term study of total and "prostatic" acid phosphatases in a patient with clinical cancer of the prostate but without evidence of skeletal metastases*

\begin{tabular}{lccccc}
\hline \hline Date & Total & $\begin{array}{c}\text { Serum acid } \\
\text { "Prostatic" }\end{array}$ & $\begin{array}{c}\text { phosphatase } \\
\text { Date }\end{array}$ & Total & "Prostatic" \\
\hline 1952 & & & 1953 & & \\
$10 / 9$ & 1.2 & 0.8 & $1 / 9$ & 2.4 & 1.4 \\
$10 / 16$ & 1.8 & 1.1 & $1 / 19$ & 3.3 & 2.3 \\
$10 / 23$ & 1.5 & 0.8 & $1 / 30$ & 3.2 & 2.3 \\
$10 / 28$ & 1.8 & 1.2 & $2 / 5$ & 2.3 & 1.6 \\
$11 / 6$ & 2.3 & 1.4 & $2 / 12$ & 2.9 & 1.7 \\
$11 / 13$ & 2.2 & 1.4 & $2 / 18$ & 3.4 & 2.4 \\
$11 / 28$ & 3.1 & 2.1 & $2 / 27$ & 3.6 & 2.5 \\
$12 / 4$ & 2.5 & 1.8 & $3 / 5$ & 3.0 & 2.2 \\
$12 / 15$ & 2.2 & 1.6 & $3 / 13$ & 2.3 & 1.5 \\
$12 / 18$ & 3.0 & 2.3 & $3 / 20$ & 2.4 & 2.0 \\
$12 / 31$ & 2.0 & 1.0 & $3 / 27$ & 2.9 & 2.2 \\
\hline
\end{tabular}

* The observations supplement those illustrated in Figure 4.

enzyme activity. The failure of stilbestrol to do so is also illustrated in Figure 9, showing parallel

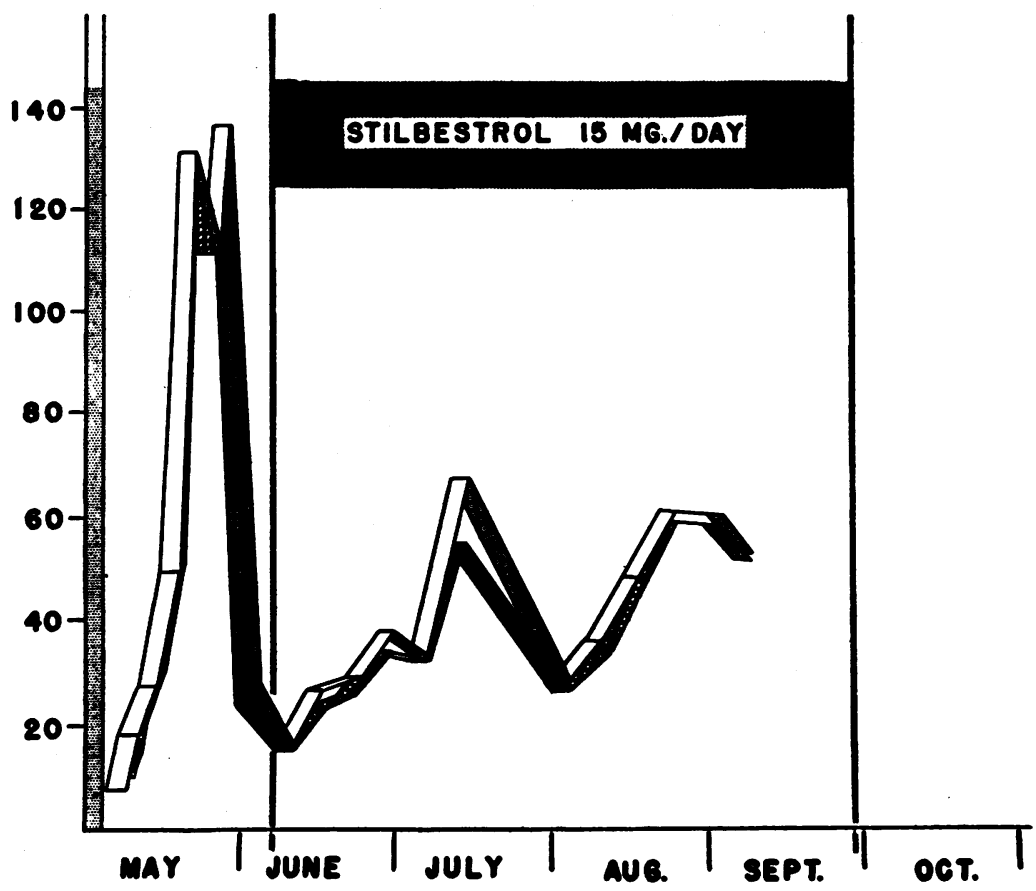

Fig. 8. Patrent di P., White, Male of 72

In good health until March, 1952, when gross hematuria was noted. There was an enlarged, stony-hard prostate and elevated acid phosphatase. The patient was transferred to the Holy Ghost Hospital from another institution where no therapy had been given. No hematuria was found on admission, and the examination of the prostate was as noted. X-ray series at time of admission showed osteolytic lesion in the seventh dorsal vertebra and in the left ramus of the pubis. The patient was ambulatory throughout his hospitalization. Light ribbon is $\mathbf{T}$ phosphatase and checkered ribbon is $\mathbf{P}$ phosphatase in King-Armstrong units. 


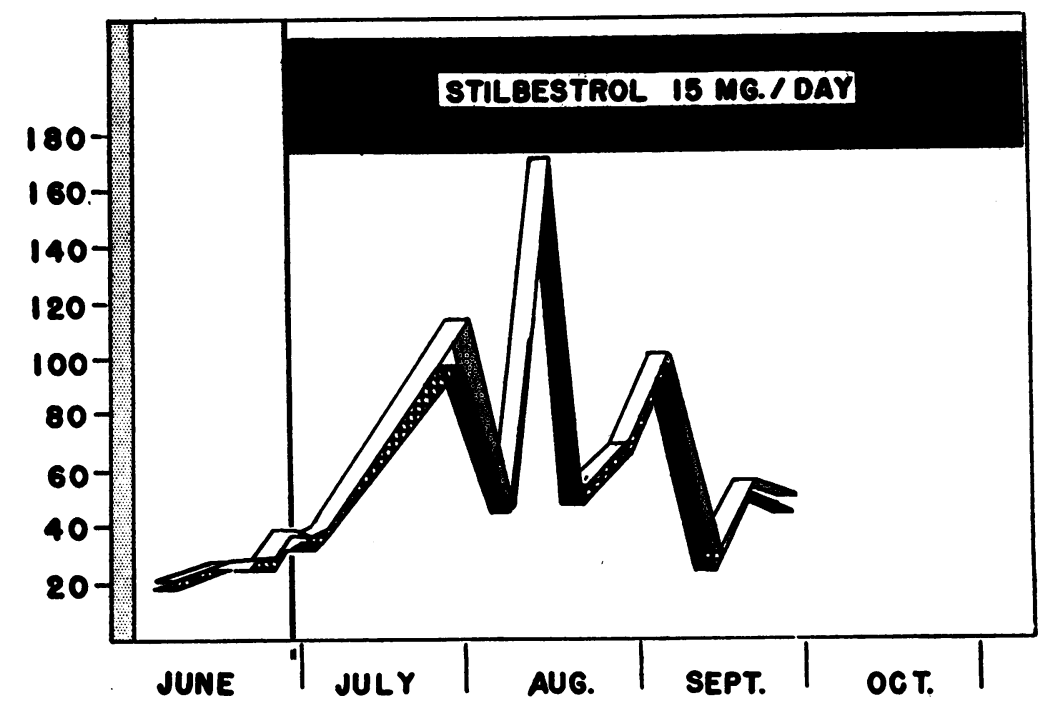

Fig. 9. Patient H., Colored, Male of 87

Generalized arteriosclerosis, pain in pelvic and lumbar areas, enlarged and tender prostate with nodular induration on right upper pole. Elevated acid phosphatase and biochemical course shown in Figure 9. Clinically there was marked improvement during Stilbestrol therapy with disappearance of pelvic and lumbar pain and return of patient to normal activity. Light ribbon is $\mathrm{T}$ phosphatase and checkered ribbon is $\mathbf{P}$ phosphatase in King-Armstrong units.

fluctuations at highly pathological levels in a patient during clinically unsuccessful estrogen therapy.

\section{DISCUSSION}

The levels in the blood serum of acid phosphatase elaborated by normal and neoplastic prostatic cells are subject to a great many regulating factors. To name a few, one must consider the rate of enzyme production by the cells, the permeability of the cells, the solubility of the enzyme, the circulatory and anatomical conditions in and around the cancerous prostate and its metastases, possible activating or inhibiting substances in tissues, lymph, and blood stream, the rate of diffusion from the vascular channels and the rate of absorption of the enzyme by various tissues, its destruction by such tissues and perhaps its excretion from the body. In spite of the complexity of this physiological situation, determinations of serum acid phosphatase by the King-Armstrong method have become of considerable usefulness to the clinician dealing with prostatic cancer. The clinical specificity of this determination is considerable but as was pointed out in the introduction, its sensitivity is of low degree.
Serum "prostatic" acid phosphatase. The evidence that, by means of the L-tartrate inhibitor as employed in the present study, one measures largely but not exclusively, prostatic acid phosphatase, is based on both experimental and clinical data.

Complete inhibition of prostatic gland acid phosphatase is obtained in vitro with L-tartrate $(8,9)$. In addition, this inhibitor is fully active on prostatic acid phosphatase added to human sera $(8,9)$.

It appears that in man the blood serum contains very little acid phosphatase from non-prostatic sources which is inhibited by L-tartrate. Thus, the sera of women contains very often not a trace of L-tartrate-inhibited acid phosphatase. The small amounts which are present in other women are undoubtedly due to enzyme from organs such as spleen or liver (9) which is inhibited by L-tartrate.

Clinical evidence supports the view that the prostate gland is the predominant source in the serum of L-tartrate-inhibited acid phosphatase. Thus, prostatic massage results in a significant increase of the fraction of serum acid phosphatase inhibited by L-tartrate more often than of the total acid phosphatase. The fact that palpation of the prostate in 10 per cent of patients without cancer of the prostate does give rise to a subsequent increase in 
serum acid phosphatase is known $(10,11)$. In cancer of the prostate the "prostatic" acid phosphatase in the serum is elevated on every occasion when one encounters a high serum acid phosphatase. Serum "prostatic" acid phosphatase behaves in a parallel fashion to the total acid phosphatase under varying regimes of sex hormone therapy.

Clinical sensitivity of "prostatic" acid phosphatase in serum. The serum level of this "prostatic" acid phosphatase appears to be a far more sensitive index of prostatic activity than is the serum level of the total acid phosphatase determined by the King-Armstrong method.

This is deduced from the observations that the effects of prostatic massage are not evident from the total enzyme levels as often as from the "prostatic" serum enzyme levels, that the "prostatic" serum acid phosphatase was found increased in some cases of proven cancer of the prostate without demonstrable bone involvement at a time when there were completely normal levels of the total serum acid phosphatase, and from the fact that the "prostatic" serum enzyme rose with androgen administration and fell with estrogen therapy at times when no significant changes occurred in the total serum acid phosphatase.

The readiness with which the L-tartrate inhibited enzyme enters the blood stream from the prostate after palpation, a fact which renders this procedure more sensitive than the conventional method, also calls for great caution in avoiding the taking of blood specimens for this determination within several hours after the prostate has been manipulated.

The observations reported in this paper are presented with the conclusion that this method probably comes closer to measuring true prostatic acid phosphatase in serum than do previous ones.

\section{SUMMARY}

1. The principle of inhibition of an acid phosphatase fraction in prostatic tissue by L-tartrate has been applied to the serum acid phosphatase in patients with various non-prostatic diseases and in patients with benign prostatic hypertrophy, chronic prostatitis and proven cancer of the prostate.

2. The normal distribution of this serum enzyme fraction in elderly men and women has been determined, 0 to 0.5 units per $100 \mathrm{ml}$. serum.
3. Palpation of the prostate was followed by a transient rise in "prostatic" acid phosphatase of serum (up to 1.5 units per $100 \mathrm{ml}$. serum) in the absence, as a rule, of abnormal values of serum total acid phosphatase.

4. In untreated cancer of the prostate, seven patients with bone metastases exhibited abnormal values for both total and "prostatic" serum acid phosphatase.

5. In four out of five patients with untreated cancer of the prostate without demonstrable metastases, abnormal values for "prostatic" acid phosphatase in the presence of normal serum acid phosphatase levels were observed.

6. Long-term studies of hormonal therapy of cancer of the prostate gland demonstrate a close parallel behavior of both total and "prostatic" serum acid phosphatase.

7. In these studies, abnormal "prostatic" acid phosphatase values in serum preceded and succeeded the appearance and subsequent disappearance of pathological levels of the total acid phosphatase.

8. On the basis of the present data, it is considered that the clinical application of the method of Fishman and Lerner for "prostatic" acid phosphatase in serum may offer real advantages over previous ones.

\section{REFERENCES}

1. Fishman, W. H., Lerner, F., and Homburger, F., Studies on prostatic cancer employing a method for estimating serum acid phosphatase of prostatic origin. Proc. of the American Association for Cancer Research, 1953, 1, 17.

2. Gutman, A. B., and Gutman, E. B., An "acid" phosphatase occurring in the serum of patients with metastasizing carcinoma of the prostate gland. J. Clin. Invest., 1938, 17, 473.

3. Gutman, A. B., Serum "acid" phosphatase in patients with carcinoma of the prostate gland: Present status. J. A. M. A., 1942, 120, 1112.

4. Bodansky, M., and Bodansky, O., In Biochemistry of Disease, New York, The Macmillan Co., 1952, p. 287.

5. Fischmann, J., Chamberlin, H. A., Cubiles, R., and Schmidt, G., Quantitative determinations of acid phosphatase in the prostate under various normal and pathological conditions; preliminary report. J. Urol., 1948, 59, 1194.

6. Herbert, F. K., The differentiation between prostatic phosphatase and other acid phosphatases in pathological human sera. Biochem. J., 1944, 38, xxiii. 
7. Abdul-Fadl, M. A. M., and King, E. J., The inhibition of acid phosphatases by formaldehyde and its clinical application for the determination of serum acid phosphatases. J. Clin. Path., 1948, 1, 80.

8. Fishman, W. H., and Lerner, F., A method for estimating serum acid phosphatase of prostatic origin. J. Biol. Chem., 1953, 200, 89.

9. Abdul-Fadl, M. A. M., and King, E. J., Properties of the acid phosphatases of erythrocytes and of the human prostate gland. Biochem. J., 1949, 45, 51.

10. Hock, E., and Tessier, R. N., Elevation of serum acid phosphatase following prostatic massage. J. Urol., 1949, 62, 488.

11. Daniel, O., and Van Zyl, J. J., Rise of serum-acidphosphatase level following palpation of the prostate. Lancet, 1952, 1, 998. 